EDITORIAL

\title{
The ECG in acute coronary syndromes: new tricks from an old dog
}

H S Gurm, E J Topol

The ECG remains the pre-eminent test for myocardial ischaemia, directing therapeutic management and prognostic stratification.

Heart 2005;91:851-853. doi: 10.1136/hrt.2004.047258

information on the integrity of the microcirculation, the significance of which has been only recently recognised.

Impaired myocardial microperfusion has been shown to be a major predictor of adverse outcome in patients undergoing reperfusion therapy. ${ }^{7}$ Complete resolution of ST changes has emerged as a simple yet robust marker of microvascular perfusion with the degree of ST resolution being strongly correlated with myocardial blush grade on angiography. ${ }^{8}$ Numerous groups have demonstrated a poor short and long term outcome in patients that have persistent ST elevation despite successful restoration of TIMI (thrombolysis in myocardial infarction) grade 3 flow in the infarct related artery by mechanical or pharmacological means..$^{9-14}$ Cura and colleagues recently reported the results of RESTART (resolution of ST segment after reperfusion therapy), a substudy of the GUSTO (global use of strategies to open occluded coronary arteries) $\mathrm{V}$ trial. $^{15}$ In this prospective study of 1764 patients randomised to full dose reteplase or half dose reteplase and abciximab, patients with $>70 \%$ ST resolution at 60 minutes had a 30 day mortality of $2.1 \%$, those with partial resolution $(30-70 \%) 5.2 \%$, those with no ST resolution $5.5 \%$, while those with worsening ST elevation had a mortality of $8.1 \%$. Persistent ST segment elevation may be a more sensitive marker of impaired microcirculation with at least one study demonstrating worst outcome in those with both poor myocardial blush and persistent ST elevation, the best outcome in those with resolution of both, and an intermediate outcome in those with normal blush but persistent ST elevation. ${ }^{16}$ Furthermore, compared with myocardial blush, normalisation of ST segment is a better predictor of early recovery of left ventricular function. Indeed, in a small study, failure to resolve ST segment was closely related to defects on myocardial contrast echocardiography. ${ }^{10}$ The demographic factors that predispose to persistent

An ECG not only helps in establishing the diagnosis of STEMI but also provides valuable information on infarct location, success or failure of reperfusion, as well as prognosis. ${ }^{3}$ Arterial

See end of article for authors' affiliations

....................

Correspondence to: Eric J Topol, MD, Department of Cardiovascular Medicine, Cleveland Clinic Foundation, Cleveland, OH 44195 USA; topole@ ccf.org occlusion at particular anatomical sites is associated with specific ECG patterns and imparts correspondingly varying degrees of short or long term mortality hazard. ${ }^{4}$ The majority of patients with ST elevation MI have ST depression in reciprocal leads. This finding appears to be associated with an increased hazard of adverse long term outcome, at least in some series. ${ }^{56}$ While the utility of ECG in screening for epicardial coronary arterial occlusion has been long recognised, the ECG provides accretive
Abbreviations: ACS, acute coronary syndromes; $C A B G$, coronary artery bypass graft surgery; FRISC-II, fast revascularization during instability in coronary artery disease; GUSTO, global use of strategies to open occluded coronary arteries; NSTEMI, non-ST elevation myocardial infarction; PARAGON-B, platelet Ilb/Illa antagonism for the reduction of acute coronary syndrome events in a global organization network; PCl, percutaneous coronary intervention; RESTART, resolution of ST segment after reperfusion therapy; RITA 3, randomized intervention trial of unstable angina; STEMI, ST elevation myocardial infarction; TACTICS-TIMI-18, treat angina with Aggrastat and determine cost of therapy with an invasive or conservative strategy; TIMI, thrombolysis in myocardial infarction


ST segment elevation remain somewhat ambiguous, but include older age and low systolic blood pressure at presentation, ${ }^{17}$ anterior myocardial infarction, ${ }^{15}$ as well as prolonged time to reperfusion. ${ }^{18}$ Given its universal availability, simplicity and proven superiority to angiographic measures, the ECG continues to be the platinum standard for assessing adequacy of myocardial reperfusion in STEMI.

\section{NSTEMI ACUTE CORONARY SYNDROMES}

The ECG at presentation in NSTEMI ACS not only helps differentiate it from STEMI but the nature of ST changes itself provides key diagnostic and prognostic clues. Savonitto and colleagues divided 12142 patients with ACS enrolled in GUSTO-IIb trial into those with T wave inversion (22\%), ST elevation (28\%), ST depression (35\%), and a combination of ST elevation and depression (15\%). ${ }^{19}$ Patients with T wave inversion were most likely to have angiographically normal coronary arteries (19\%) while those with ST depression were more likely to have three vessel disease (36\%). One month mortality showed a gradient with the lowest incidence in those with only $\mathrm{T}$ wave changes (1.7\%), intermediate in those with ST elevation $(5.1 \%)$ or only depression $(5.1 \%)$, and worst in those with both elevation and depression (6.6\%). Further similar trends in six month mortality were observed with the mortality rate being $3.4 \%$ in those with $\mathrm{T}$ wave changes, $6.8 \%$ in those with ST elevation, $8.9 \%$ in those with ST depression, and $9.1 \%$ in those with both ST depression and elevation. These mortality associations remained significant after adjusting for elevated creatine kinase (CK) MB and for other variables that were predictors of 30 day mortality. Similarly, Kaul and colleagues demonstrated the severity of ST depression ( $>2 \mathrm{~mm}$ in two contiguous leads) to be associated with an almost 6-10 fold hazard of one year death. $^{20}$

While these early studies established a role for using the ECG in risk stratification in NSTEMI ACS, the parallel development and validation of troponin as a marker of myonecrosis and prognosis required retesting this hypothesis in a more contemporary setting. Kaul and colleagues evaluated the six month outcome among 959 patients enrolled in the troponin $\mathrm{T}$ substudy of the PARAGON-B (platelet IIb/IIIa antagonism for the reduction of acute coronary syndrome events in a global organization network) trial and demonstrated the complementary value of troponin status and quantitative ST depression. ${ }^{21}$

The next paradigm shift in management of NSTEMI ACS was the validation of an early invasive strategy on a background of potent antiplatelet treatment. It was soon recognised that the presenting ECG continued to provide additional prognostic information. Retrospective data from the FRISC-II (fast revascularization during instability in coronary artery disease) trial demonstrated that the benefit of early revascularisation was proportional to the degree of ST deviation with an almost halving of the risk of death and myocardial infarction among those with the most extensive ST changes. This association appeared independent of age, sex, or troponin status. ${ }^{22}$ In another analysis from the same study the benefit of early revascularisation was most pronounced in those with both ST depression and troponin elevation, intermediate in those with only one of the two factors, and uncertain in those with neither. ${ }^{23}$ The discrepant outcome between $\mathrm{T}$ wave inversion and ST depression was confirmed even in a cohort treated with early invasive therapy. In a Swiss study of 1450 patients, the in-house mortality was $4 \%$ with ST depression, 2\% with no ECG changes, and $0.2 \%$ in those with $\mathrm{T}$ wave inversions. Similar trends were seen in long term mortality. ${ }^{24}$ However, the other two pivotal trials of early invasive therapy in ACS, TACTICSTIMI- $18^{25}$ (treat angina with Aggrastat and determine cost of therapy with an invasive or conservative strategy) and RITA $3^{26}$ (randomized intervention trial of unstable angina) failed to demonstrate any difference in the effectiveness of early invasive strategy across different categories of ECG changes.

In the current issue of Heart, Kaul and colleagues ${ }^{27}$ report their findings from over 11000 patients enrolled in GUSTO$\mathrm{IIb}$ and PARAGON A and B trials. They found that revascularisation (although not randomised) was associated with an increased survival benefit only in patients with ST depression $\geqslant 1 \mathrm{~mm}$. Their findings are concordant with those from FRISC-II, but given the divergent findings from TACTICS-TIMI-18 and RITA-3, it will be premature to limit early invasive treatment to patients with ST depression only. Further, they note a difference in percutaneous coronary intervention (PCI) and coronary artery bypass graft surgery (CABG) use across the ST continuum, with a fall in PCI rate and a rise in CABG rates with worsening ST depression. This is likely a reflection of the increased incidence of three vessel disease and left main artery disease in patients with greater ST depression. The international differences in clinical practice noted by the authors are in line with previously reported variation in cardiovascular practice, with the more aggressive approach in USA being validated by the recent clinical trials. However, these differences predate the validation of an invasive strategy and hence it would be more relevant to study current international practice patterns to assess if there has been a commensurate change in use of invasive strategy globally.

Despite these limitations, the authors are to be commended for continuing the focus on the tool that has had immeasurable impact on the field of cardiology. The ECG was the first clinical tool that allowed assessment of myocardial ischaemia and despite multiple paradigm shifts in the management of ACS, it continues to be the pre-eminent test directing therapeutic management and prognostic stratification.

\section{Authors' affiliations \\ H S Gurm, E J Topol, The Department of Cardiovascular Medicine, The Cleveland Clinic Foundation, Cleveland, Ohio, USA}

We have no relevant competing interests to disclose with regard to this manuscript.

\section{REFERENCES}

1 Fye WB. A history of the origin, evolution, and impact of electrocardiography. Am J Cardiol 1994;73:937-49.

2 Alpert JS, Thygesen K, Antman E, et al. Myocardial infarction redefined-a consensus document of the joint European Society of Cardiology/American College of Cardiology committee for the redefinition of myocardial infarction. J Am Coll Cardiol 2000;36:959-69.

3 Zimetbaum PJ, Josephson ME. Use of the electrocardiogram in acute myocardial infarction. N Engl J Med 2003;348:933-40.

4 Topol E, Van de Werf F. Acute myocardial infarction; early diagnosis and management. In: Topol E, eds. Textbook of cardiovascular medicine, 2 nd ed. Philadelphia: Lippincott Williams and Wilkins, 2002:385-419.

5 Krone RJ, Greenberg H, Dwyer EM Jr, et al. Long-term prognostic significance of ST segment depression during acute myocardial infarction. The multicenter diltiazem postinfarction trial research group. J Am Coll Cardiol 1993;22:361-7.

6 Birnbaum Y, Herz I, Sclarovsky S, et al. Prognostic significance of precordial ST segment depression on admission electrocardiogram in patients with inferior wall myocardial infarction. J Am Coll Cardiol 1996;28:313-8.

7 Ito H, Maruyama A, Iwakura K, et al. Clinical implications of the 'no reflow' phenomenon. A predictor of complications and left ventricular remodeling in reperfused anterior wall myocardial infarction. Circulation 1996;93:223-8.

8 van't Hof AW, Liem A, Suryapranata $H$, et al. Angiographic assessment of myocardial reperfusion in patients treated with primary angioplasty for acute myocardial infarction: myocardial blush grade. Zwolle myocardial infarction study group. Circulation 1998;97:2302-6.

9 van't Hof AW, Liem A, de Boer MJ, et al. Clinical value of 12-lead electrocardiogram after successful reperfusion therapy for acute myocardial infarction. Zwolle myocardial infarction study group. Lancet 1997;350:615-9. 
10 Lepper W, Sieswerda GT, Vanoverschelde JL, et al. Predictive value of markers of myocardial reperfusion in acute myocardial infarction for followup left ventricular function. Am J Cardiol 2001;88:1358-63.

11 Matetzky S, Freimark D, Chouraqui P, et al. The distinction between coronary and myocardial reperfusion after thrombolytic therapy by clinical markers of reperfusion. J Am Coll Cardiol 1998;32:1326-30.

12 Matetzky S, Novikov M, Gruberg L, et al. The significance of persistent ST elevation versus early resolution of ST segment elevation after primary PTCA J Am Coll Cardiol 1999;34:1932-8.

13 Schroder K, Wegscheider K, Zeymer U, et al. Extent of ST-segment deviation in a single electrocardiogram lead $90 \mathrm{~min}$ after thrombolysis as a predictor of medium-term mortality in acute myocardial infarction. Lancet 2001;358:1479-86.

14 Stone GW, Peterson MA, Lansky AJ, et al. Impact of normalized myocardial perfusion after successful angioplasty in acute myocardial infarction. J Am Coll Cardiol 2002;39:591-7.

15 Cura FA, Roffi M, Pasca N, et al. ST-segment resolution 60 minutes after combination treatment of abciximab with reteplase or reteplase alone for acute myocardial infarction (30-day mortality results from the resolution of STsegment after reperfusion therapy substudy). Am J Cardiol 2004:94:859-63.

16 Poli A, Fetiveau R, Vandoni P, et al. Integrated analysis of myocardial blush and ST-segment elevation recovery after successful primary angioplasty: realtime grading of microvascular reperfusion and prediction of early and late recovery of left ventricular function. Circulation 2002;106:313-8.

17 Claeys MJ, Bosmans J, Veenstra L, ef al. Determinants and prognostic implications of persistent ST-segment elevation after primary angioplasty for acute myocardial infarction: importance of microvascular reperfusion injury on clinical outcome. Circulation 1999:99:1972-7.

18 De Luca G, van't Hof AW, de Boer MJ, et al. Time-to-treatment significantly affects the extent of ST-segment resolution and myocardial blush in patients with acute myocardial infarction treated by primary angioplasty. Eur Heart $J$ 2004;25: 1009-13.

19 Savonitto S, Ardissino D, Granger CB, et al. Prognostic value of the admission electrocardiogram in acute coronary syndromes. JAMA 1999;281:707-13.
20 Kaul P, Fu Y, Chang WC, et al. Prognostic value of ST segment depression in acute coronary syndromes: insights from PARAGON-A applied to GUSTO$\mathrm{llb}$. PARAGON-A and GUSTO Ilb investigators. Platelet Ilb/Illa antagonism for the reduction of acute global organization network. J Am Coll Cardiol 2001;38:64-71.

21 Kaul P, Newby LK, Fu Y, et al. Troponin T and quantitative ST-segment depression offer complementary prognostic information in the risk stratification of acute coronary syndrome patients. J Am Coll Cardiol 2003:41:371-80.

22 Holmvang L, Clemmensen P, Lindahl B, et al. Quantitative analysis of the admission electrocardiogram identifies patients with unstable coronary artery disease who benefit the most from early invasive treatment. J Am Coll Cardiol 2003:41:905-15.

23 Diderholm E, Andren B, Frostfeldt G, et al. The prognostic and therapeutic implications of increased troponin T levels and ST depression in unstable coronary artery disease: the FRISC II invasive troponin T electrocardiogram substudy. Am Heart J 2002;143:760-7.

24 Mueller C, Neumann FJ, Perach W, et al. Prognostic value of the admission electrocardiogram in patients with unstable angina/non-ST-segment elevation myocardial infarction treated with very early revascularization. Am J Med 2004:117:145-50.

25 Cannon CP, Weintraub WS, Demopoulos LA, et al. Comparison of early invasive and conservative strategies in patients with unstable coronary syndromes treated with the glycoprotein Ilb/Illa inhibitor tirofiban. NEngl J Med $2001 \cdot 344: 1879-87$

26 Fox KA, Poole-Wilson PA, Henderson RA, et al. Interventional versus conservative treatment for patients with unstable angina or non-ST-elevation myocardial infarction: the British Heart Foundation RITA 3 randomised trial. Randomized intervention trial of unstable angina. Lancet 2002;360:743-51

27 Kaul P, Newby LK, Fu Y, et al. Relation between baseline risk and treatmen decisions in non-ST elevation acute coronary syndromes: an examination of international practice patterns. Heart 2005;91:876-81.

\section{IMAGES IN CARDIOLOGY}

doi: $10.1136 /$ hrt.2004.052142

\section{"Sea anemones" on a degenerated bicuspid aortic valve}

A 72 year old man was operated on for a severely stenotic (gradient $120 \mathrm{~mm} \mathrm{Hg}$ ) congenitally bicuspid aortic valve. The valve was replaced by a prosthetic valve and the resected leaflets were stored in formalin for routine pathologic analysis. Under formalin two beautiful sea anemone-like glistening white papillary tumours unfolded at the valvar surface, with all the features of papillary fibroelastomas (panels B and C). The tumours measured $5 \mathrm{~mm}$ and $9 \mathrm{~mm}$, respectively.
When the valve leaflets were taken out of the formalin container, the fibroelastomas collapsed like sea anemones do at low tide (panel A, arrow); an image which corresponded with the aspect of the valves at the time of surgery.
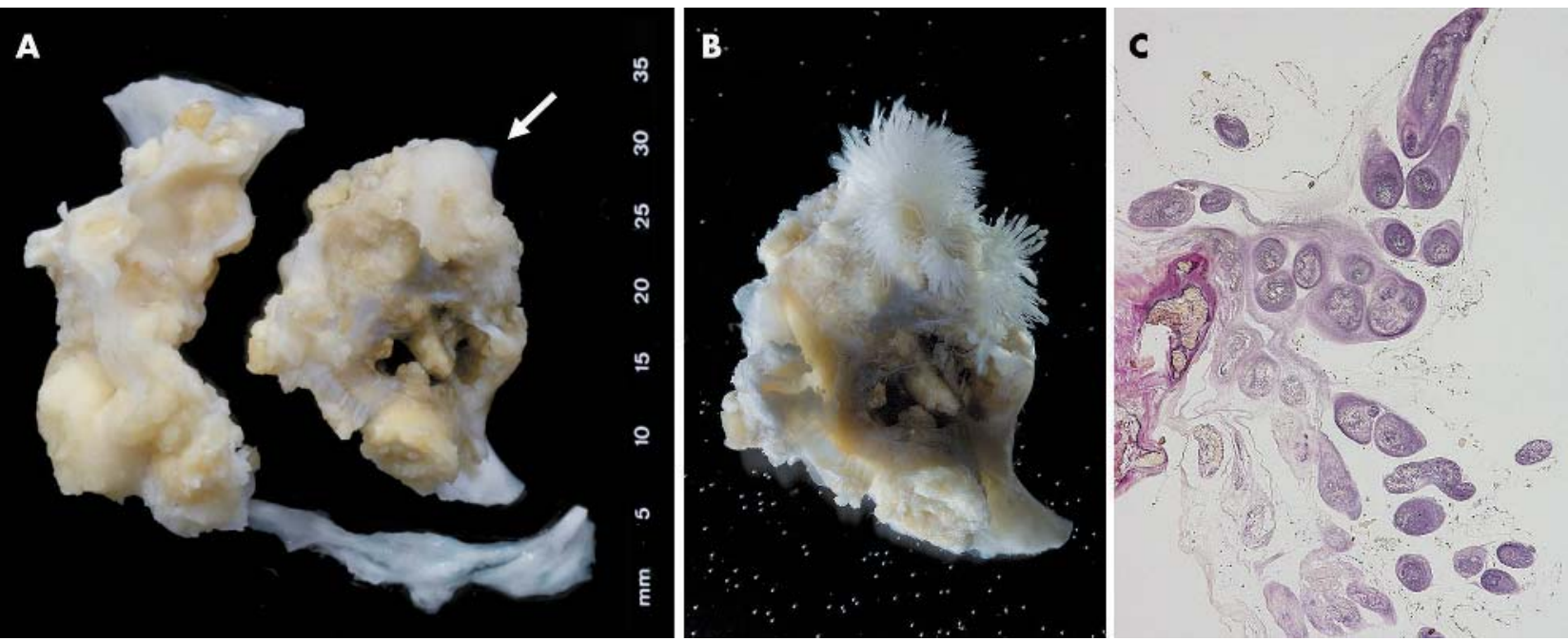

(A) Overview of resected valve tissue. Photo is of a "dry specimen". Arrow indicates collapsed fibroelastomas. (B) Detail of leaflet with unfolded fibroelastomas. Photo is of a wet specimen (placed in water). (C) Histology of fibroelastoma showing cell-poor, elastin-rich (black) papillary structures (elastic van Gieson stain $\times 24$ ). 